\title{
The effect of the math emporium instructional method on students' performance in college algebra
}

\author{
Kathy Cousins-Cooper, Katrina N. Staley, Seongtae Kim, Nicholas S. Luke \\ Department of Mathematics, North Carolina A\&T State University \\ For correspondence: cousinsk@ncat.edu
}

\begin{abstract}
This study aims to investigate the effectiveness of the Emporium instructional method in a course of college algebra and trigonometry by comparing to the traditional lecture method.The math emporium method is a nontraditional, instructional method of learning math that has been implemented at several universities with much success and has been shown to improve the performance of students taking college algebra and trigonometry courses. In the math emporium method, students spend time working on the problems using interactive software. The students are able to get immediate feedback on their progress by soliciting help from the instructors. This method encourages students to be actively involved in the acquiring of their knowledge. In this study, we compare the performance of students using the math emporium method to that of students using the traditional, lecture method. Performance was measured using posttest scores and the final course grades. We found that the math emporium method shows promise to improving students' performance in college algebra and trigonometry classes.
\end{abstract}

Keywords: Achievement, Algebra, computer-assisted learning, cooperative learning, math emporium

\section{Introduction}

College Algebra is of utmost importance to students' success in other courses. There is agreement in the literature that algebra is critically important to student success in high school and college (Rakes et al., 2010).However, algebra is a subject many students may find difficult. Many times the failure rate of students is high. Failure rates of students in college algebra courses are much higher than failure rates in other freshman level courses (Herriott \& Dunbar, 2009). College algebra has been singled out as the course responsible for low retention of students (Sheldon, 2008). Therefore, since algebra is vitally important to a students' academic future, it is important to focus on the instructional methods used to deliver algebraic subject matter. Algebra is recognized as a subject that is difficult to learn and to teach well (Stacey et al. 2004; Watson 2009; Drijvers et al. 2014). Due to the decline in math achievement through the years when students' begin to study algebra, the effectiveness of traditional instruction is questionable (Rakes et al., 2010; National Mathematics Advisory Panel, 2008). This study aims to investigate the effectiveness of the Emporium instructional method in a course of college algebra and trigonometry by comparing to the traditional lecture method.

The instructional delivery method of college algebra and trigonometry is important because it affects the students' dispositional learning and achievement. Due to low retention rates in freshman-level mathematics courses, mathematics educators continue to seek ways to improve student performance in algebra class. Students' beliefs and expectations regarding the difficulty of mathematics, their levels of engagement, and their likelihood or perceived value of success can profoundly influence their achievement in mathematics (Lipnevich et al., 2011; Singh, Granville, \& Dika, 2002; Stevenson \& Newman, 1986). If a student has a positive attitude toward mathematics, he can overcome difficulties through persistence, and he will be more likely to persist if he has a positive attitude. The 
teaching method can affect students' attitudes. Mathematics anxiety and negative attitudes can have a negative impact on student success in university-level mathematics courses (Hegeman, 2015). Furner and Gonzalez-DeHass (2011) recommend that educators establish a class climate that emphasizes thinking, encourages students to ask questions, and allows students to engage in activities that allow them to learn from and correct their mistakes. The math emporium instructional method does encourage students to think, ask questions, and engage in class activities.

The math emporium method is one that has been described as the "silver bullet of education." (Twigg, 2011) It is a method that has been implemented at numerous universities with much success. The math emporium method has shown promise in improving the performance of students taking college algebra and trigonometry courses (Twigg, 2011). This paper will provide empirical insight on the effectiveness of implementing the math emporium method of instruction versus the traditional lecture method.

The math emporium method is an interactive instructional method of learning math. It was developed and first implemented at Virginia Tech (Twigg, 2011). Since its inception in 1997, the math emporium method has spread to many other colleges and universities. In the math emporium classroom, students spend time learning mathematical content and working on the problems using interactive software. The students are able to get immediate feedback on their progress by soliciting help from the instructors. The students are not watching an instructor work problems on the board, but the students are working the problems themselves with the instructors and teaching assistants facilitating their progress. This setting encourages students to be actively involved in the acquiring of their knowledge. Students that are not actively involved in developing knowledge receive information passively and are less motivated (Zakaria et al., 2013).There are several aspects of the emporium classroom, which have been examined, and they include computer assisted instruction and online work, cooperative learning, and individualized instruction.

The use of computers in the classroom and online environments for teaching mathematics has had mixed results. Burch and Kuo (2010) found that those students given online homework performed better on exams and had a higher rate of retention as compared to those students given traditional paper homework. However, Mathai and Olsen (2013) found that online homework was beneficial to the incoming higher-skilled group, whereas, the lower-skilled students did not benefit from online homework. Spradlin and Ackerman (2010) compared the performance of developmental math classes that used computer-assisted instruction and those that did not. In this study, they found that there was no statistical difference in the posttest scores of those students receiving computer-assisted instruction and those that did not. However, they found that the females outperformed the males in both modes of instruction. Drijvers et al. (2014) investigated the effect of online tasks for algebra and found that the students using the online tasks performed below the students that did not use the online tasks. Tienken and Maher (2008) found that computer assisted-instruction did not improve student performance significantly and that those that did not receive computer-assisted instruction outperformed those that did in two categories. Vilardi and Rice (2014) analyzed the effectiveness of technology-assisted courses in a pre-calculus algebra course and found that students enrolled in the technology-assisted courses did not perform at the same level as the students in the traditional setting.

The math emporium method incorporates learning activities designed to include peer and instructor discussion, which has been documented to increase interactive student engagement and learning (Hake, 1998). It also develops and encourages peer-facilitated learning, which has been shown to promote communication and cooperative learning among (Shechtman et al., 2010; Slavin, 2010). Robinson et al. (2005) found that peer tutoring in mathematics is a useful approach to improve the achievement level of African American and White students and those tutoring and those being 
tutored improved in academic achievement and experienced positive and attitudinal and socioemotional outcomes. However, DePree (1998) found that small group instructional methods did not improve achievements rates in algebra, but it did have a positive impact on course completion rates. While cooperative learning is widely supported by experts as an essential component to successful math instruction (NCTM, 2006; National Mathematics Advisory Panel, 2008) it fails without properly unstructured group work, little individual accountability, and no group goals (Fullilove and Treisman, 1990; Slavin, 2010). In fact, the long-term effect of this absence of structures to promote higher level interaction is that students often develop the habit of turning group work into simply sharing answers rather than trying to explain ideas to each other (Antil et al, 1998; Gillies and Ashman, 2003), which has been found to inhibit, not aid, the learning of math (Gillies and Ashman, 2003).

The traditional lecture method is one that is centered on the instructor. The instructor typically does not assess whether the student understands the material while the instructor is lecturing. In addition, some students are intimidated from participating in a lecture class, andas a result, this type of student is not engaged in the lesson. The traditional lecture method often does not provide students with meaningful experiences in doing math, but students sit passively watching the instructor work problems. Contrast the lecture method with the math emporium method, in which students spend time actively working the problems. When the students encounter difficulty when working a problem, the students can receive assistance by signaling to an instructor. Instead of working homework problems away from the instructor who can answer the question, the student can make progress in the homework without being stymied in solving a problem. Also, the math emporium method encourages students to work together in the form of peer tutoring which builds a community of learners. The more time students spend interacting with classmates, the higher the satisfaction level and interacting in an inclusive learning community is a suggested practice to enhance student learning (Chickering \& Gamson, 1987; Blimling \& Whitt, 1999).

\section{Statement of the Problem}

The implementation of the math emporium within the college algebra \& trigonometry courses was an effort to remedy the poor student performance and retention that was evident with the lecture method.The math emporium instructional method is an active learning method, and active learning has been identified as a good practice for faculty to foster student learning (Goodman et al, 2011; Chickering \& Gamson, 1987; Blimling \& Whitt, 1999). The more actively involved a student is in the mathematics classroom, the more likely the student will be motivated to learn.

RESEARCH QUESTIONS. On the basis of the preceding review of the literature, this study addresses the following research questions:

1. Do students enrolled in the emporium college algebra classes perform significantly better than students enrolled in the traditional lecture college algebra class as measured by performance on a posttest?

2. Do students enrolled in the emporium college algebra classes perform significantly better than students enrolled in the traditional lecture college algebra class as measured by final course grade?

RESEARCH HYPOTHESES. The following hypotheses were formulated to guide the study and test at a $5 \%$ level of significance:

1. There is no significant difference in the performance of the students in the Emporium college algebra class as compared to those students in the Traditional lecture class on a posttest 
2. There is no significant difference in the performance of the students in the Emporium college algebra class as compared to those students in the Traditional lecture class in final course grades.

\section{Design of the Study}

To answer the first question, we used a quasi-experimental research design. The quasi-experimental research design may be just as effective for studying student achievement in algebra as the randomized experiment. (Rakes et al, 2010). We used a pretest, the students' Math SAT score, and the students' ACT score to obtain information on the level of understanding that the students had upon entering the class, and we used a posttest and the students' final course grade to measure the students' level of growth in their algebraic thinking during their experience in their college algebra class.

\section{Method}

Participants. The participants in this study were students enrolled in one of 66 sections of a course in college algebra offered between the fall 2013 and the spring 2015 semesters. The majority (approximately 65\%) of subjects in our study were female. Forty-one of these sections were taught using the emporium model of instruction and the other twenty-five were taught using the traditional model of instruction. Prior to enrolling in the college algebra courses, the students were not informed as to which method of instruction the course would be using. Therefore, preference of an instructional method was not a factor in the students' selection of which section to enroll. The study participants were informed as to the instructional method that would be used on the first day of class.

Control/Experimental Groups. The control group consisted of twenty-five sections of college algebra taught using the traditional lecture method. Students enrolled in the traditional, lecture sections of college algebra met with their instructor for three hours per week. For each traditional section, there was only one instructor and no GTAs (Graduate Teaching Assistants) assigned. The instructors for the traditional sections taught the same content and assigned the same homework as the emporium sections; however, each of these instructors developed their own tests and quizzes, and employed their own grading standards.

Procedure. The experimental group consisted of forty-one sections of college algebra taught using the emporium method. Students enrolled in the emporium instructional sections met four hours per week total. For three of these hours, students met in a classroom in which each student sat at a computer and worked through the class assignments. The emporium classroom, where course delivery occurred, is a computer lab with workstations. A workstation included a modular desk, a wheeled chair, and a networked computer for a student to work through online instructional modules. Each lab was equipped with thin-client terminals to facilitate students' interactive learning of course modules. Each class was staffed with an instructor and enough GTAs to have a minimum ratio of one instructor or GTA for every twelve students.

During class time, students worked through their assignments and were able to ask the instructors and graduate teaching assistants (GTAs) questions about their work. To ask a question, the students would place a cup on top of the desk to signal to the instructors and GTAs that they had questions. Sometimes the instructors and GTAs were not able to get to a student immediately and during their wait time, students were encouraged to ask each other questions. The instructors and GTAs answered the students' questions on homework and tutorial questions, but not on tests and quizzes. For the fourth hour of the week, the students met with one of the GTAs in a regular classroom where the focus of this hour was on completion of additional practice problems from the course workbook. 
The GTAs were advised to allow the students to lead the process in solving the problem while the GTA facilitates the process.

Much effort was used to ensure that the Emporium courses were all the same. The same assignments and same grading scale were used for each section. All of the assignments for the Emporium students were online except for the workbook assignments. The workbook was the only assignment that allowed the instructors to view a student's step-by-step procedure to solve the problems. The students were not allowed to take a module test unless the student had completed all problems in the corresponding section of the workbook. It should be noted that some of the Emporium instructors graded for accuracy in the workbook, while others graded for completion.

There were six modules for this college algebra course developed by three math faculty members using Pearson's MyLabsPlus as a software platform for course delivery and management. Each course module consisted of a pretest, instructional videos, workbook examples and exercises, homework problems, a quiz, a practice test, and a module test. To start a module in a course, a student was required to take the module pre-test to assess prior knowledge and mastery of the module content. If the student scored 85 or higher on the module pretest, then that student was allowed to proceed directly to the next module. Otherwise, the student was required to go through the module. Homework assignments within the module were generated based on the results of the pre-test.

Students enrolled in the traditional sections of college algebra met with their instructor for three hours per week. For each traditional section, there was only one instructor and no GTAs assigned. The instructors for the traditional sections taught the same content and assigned the same homework as the emporium sections; however, each of these instructors developed their own tests and quizzes, and employed their own grading standards.

The demographics and other characteristics of study participants are described in Table 1. The continuous variables such as high school GPA, SAT, and ACT scores are summarized by the sample mean and standard deviation. The categorical variables such as gender, class time and weekday are summarized by the frequency and percentage. To compare two instruction methods, two-sample ttests for mean and chi-square tests for proportion reported p-values where p-value $<0.05$ was considered statistically significant. As can be seen, the students in both the emporium and traditional sections had very similar gender ratio, high school GPA, SAT and ACT scores. Statistical insignificance ( $p$-value $>0.05$ ) in these variables is considered to be evidence that students randomly chose one of two teaching methods. The class time and day did show a difference between the two instruction methods.

Measures. Success in an online course can be measured by academic achievement, including the grades students earn and their performance on advanced placement examinations (Liu \& Cavanaugh, 2012). In this study, the post-test score and the course grade are the primary measure to assess students' achievement. The instrument used to measure student success were tests administered at the beginning of the semester to measure initial mathematics achievement and at the end of the semester for all sections of college algebra. The tests were designed by a team of instructors that had years of experience teaching college algebra.

In addition, this study used data provided by the University's Office of Institutional Research. The data that was provided by this office included gender, classification at the time of the course, and their current major, grade received from Math 101, current GPA, high school GPA, SAT verbal score, SAT math score, and ACT score. 
Table 1. Characteristics of study subjects between two instructional methods

\begin{tabular}{lllll}
\hline & & Emporium & Traditional & p-value \\
\hline Sample size & & $970(53.53)$ & $842(46.47)$ & \\
Gender & Female (\%) & $585(63.86)$ & $526(67.18)$ & 0.1525 \\
& Male (\%) & $331(36.14)$ & $257(32.82)$ & \\
High School & mean(sd) & $3.19(0.47)$ & $3.18(0.49)$ & 0.8383 \\
GPA & & & & \\
Cumulative & mean(sd) & $2.57(0.99)$ & $2.59(0.97)$ & 0.6912 \\
GPA & & & & \\
SAT Verbal & mean(sd) & $438.4(58.60)$ & $444.1(56.14)$ & 0.0722 \\
SAT Math & mean(sd) & $437.2(56.06)$ & $437.2(56.22)$ & 0.9931 \\
ACT & mean(sd) & $17.54(2.74)$ & $17.89(2.88)$ & 0.0920 \\
Time & $8(\%)$ & $254(29.36)$ & $103(12.23)$ & $3.29 \mathrm{E}-18$ \\
& $>8(\%)$ & $611(70.64)$ & $739(87.77)$ & \\
Weekday & MWF (\%) & $422(48.79)$ & $567(83.26)$ & $1.23 \mathrm{E}-44$ \\
& TTH (\%) & $443(51.21)$ & $114(16.74)$ & \\
\hline
\end{tabular}

\section{Data Analysis}

Descriptive statistics including mean, standard deviation, median, and quartiles were provided for all variables considered in this analysis. Two outcome variables, the post-test score and the course grade, were used to compare the effectiveness of the two instructional methods. A Wilcoxon twosample test was used for the pre-test and post-test scores when the distribution of a variable did not follow a normal distribution. A general linear regression model (GLM) was used to model the relationship between the post-test score and the two instructional methods along with other covariates such as class day, class time, high school GPA, gender, SAT Verbal score, SAT Math score, and ACT score. The residual plot of the GLM was checked for the normality assumption. Logistic regression methods including the ordinal and cumulative logistic regression (McCullagh \& Nelder, 1989) were utilized to model the relationship between the course grade and the two instructional methods along with other covariates since the course grade as a response variable was of ordinal rank from A to F. Statistical analyses in this study was performed using SAS 9.4 and R.

\section{Results}

As mentioned above, the main purpose of this paper is to compare the effectiveness of the emporium and traditional instruction methods. First, we compared the instruction methods regarding the interesting outcome variables such as pretest, posttest, course grade, and pass rate. Table 2 presents students' performance in the outcome variables between two instructional methods. Pretest and posttest scores presented mean (standard deviation) and median ( $1^{\text {st }}$ quartile $-3^{\text {rd }}$ quartile) and the $p-$ values of t-tests and Wilcoxon tests. The result shows a strong evidence that students' posttest scores in the emporium sections were higher than those in the traditional sections by approximately 12 points in mean and median ( $\mathrm{p}$-value $<0.001$ ). However, the pass rate of students between the emporium and traditional lecture sections is not statistically significant ( $p$-value $=0.3206)$ where A, B and $\mathrm{C}$ were considered as the pass status. The distribution for the emporium method is skewed to lower scores, meanwhile, the distribution for the traditional method is relatively spread out. As can be seen in Table 2, both the two-sample t-test and Wilcoxon test show that the mean and median posttest scores of the emporium method are approximately 12 points higher than those of the traditional lecture method. 
Table 2. Test score and course grade comparison between two instructional methods

\begin{tabular}{lllll}
\hline & & Emporium & Traditional & p-value \\
\hline Pretest Score & mean(sd) & $36.02(19.81)$ & $45.44(15.4)$ & $8.07 \mathrm{E}-17$ \\
& median (Q1-Q3) & $35(15-50)$ & $45(53-33)$ & $1.31 \mathrm{E}-14$ \\
Posttest Score & mean(sd) & $82.16(15.27)$ & $70.5(16.73)$ & $1.38 \mathrm{E}-27$ \\
& median (Q1-Q3) & $85(75-95)$ & $73(60-85)$ & $1.70 \mathrm{E}-33$ \\
Course Grade & A (\%) & $200(22.03)$ & $161(20.77)$ & 0.0007 \\
& B (\%) & $254(27.97)$ & $188(24.26)$ & \\
& C (\%) & $201(22.14)$ & $193(24.90)$ & \\
& D (\%) & $58(6.39)$ & $81(10.45)$ & \\
& F (\%) & $162(17.84)$ & $106(13.68)$ & \\
& W (\%) & $33(3.63)$ & $46(5.94)$ & \\
& Pass & $655(72.14)$ & $542(69.94)$ & 0.3206 \\
& Fail & $253(27.86)$ & $233(30.06)$ & \\
\hline
\end{tabular}

The emporium method achieved a higher percentage of A and B grades than the traditional method. Although the chi-square test in Table 2 shows that there is a statistically significant association between the instruction method and the course grade $(p$-value $=0.0007)$, the pass rates between the two instruction methods are statistically insignificant.

The two-sample comparison of posttest scores indicates that students in the emporium sections outperformed those in the traditional sections in the college algebra course. However, this result was attained without considering other covariates such as gender, class day and time, SAT scores, and ACT score. In a regression model framework, we examined whether the difference of posttest score between the two instructional methods was significant with considering covariates. Tables 3, 5, and 6 included all covariates in the model although some covariates are not statistically significant, which is similar to Eddy and Hogan (2014).Table 3 displays the relationship between posttest scores and independent variables via a general linear regression model. Notably, the emporium instruction method increased the average post-test score by 12.63 points ( $\mathrm{p}$-value $=5.26 \mathrm{E}-18$ ) although other covariates were included in the model. One interesting result is that gender did not make a difference in posttest score ( $p$-value $=0.5680$ ). Students in the Tuesday and Thursday $(\mathrm{TTH})$ sections earned higher average posttest score by 4.56 points $(\mathrm{p}$-value $=0.0013)$ than students who were in the Monday, Wednesday, and Friday (MWF) sections. The high school GPA and SAT Math score were also statistically significant factors for increasing the post-test score. The students' performance in fall 2013 was significantly lower than other semesters, which is partially due to the launching semester. The significant effect of the emporium method was not altered with the ACT score instead of the SAT Verbal and Math scores in the regression model where the ACT score was a statistically significant factor $(\mathrm{p}$-value $=0.0041)$. The Q-Q plot of the residuals of the GLM in Table 3 showed a slightly skewed left distribution so we checked the outliers and performed a robust linear regression analysis. The result of the robust regression is not reported here since it was almost equivalent to that of Table 3.

One salient feature of the emporium method is that students have the opportunity to have multiple attempts for the test, where instructors control the maximum number of attempts. Table 4 shows the distribution of attempts and the mean and median test scores for each attempt. Sixty one percent of emporium students attempted the posttest only one time and the remaining students attempted at least twice. One student attempted the test 4 times, and another student attempted 5 times. The 
Table 3. Relationship between the posttest score and the instructional method with covariate adjustment via general linear regression model

\begin{tabular}{lll}
\hline Variable (categories) & Estimate \pm SE & p-value \\
\hline Intercept & $47.13 \pm 5.65$ & $3.72 \mathrm{E}-16$
\end{tabular}

Variation between semesters (reference level: Spring 2015)

Fall 2013

Spring 2014

Fall 2014

Class time (reference level: non-8 o'clock class)

8 o'clock

Class day (reference level: MWF class)

$\mathrm{TTH}$

Gender (reference level: male)

Female

\author{
High School GPA \\ SAT Verbal \\ SAT Math
}

$\begin{array}{ll}-15.67 \pm 1.84 & 1.02 \mathrm{E}-16 \\ -0.05 \pm 1.52 & 0.9761 \\ 1.51 \pm 1.7 & 0.3738\end{array}$

$-1.81 \pm 1.22$

0.1387

$3.02 \pm 1.12$

0.0071

Instruction method (reference level: Traditional lecture)

Emporium

$10.56 \pm 1.28$

8.17E-16

fourth and fifth attempts were likely to be related to technical glitches while taking the exam, such as a loss in internet connection. Our concern regarding comparing the two instructional methods was the effect of multiple attempts on the test scores. However, the data revealed an opposite result. The average posttest score of the students who attempted a single time was 84.7 points and that of the students who attempted multiple times was 77.4 points. This difference was statistically significant (p-value $<0.0001$ ).

Table 4. Number of attempts for posttest in the emporium method

\begin{tabular}{llllll}
\hline Attempt & 1 & 2 & 3 & 4 & 5 \\
\hline $\mathrm{n}(\%)$ & $381(61.3)$ & $162(26)$ & $77(12.4)$ & $1(0.2)$ & $1(0.2)$ \\
mean(SD) & $84.7(13.9)$ & $76.7(18.6)$ & $79(13.2)$ & $90.7(-)$ & $54.7(-)$ \\
median(Q1-Q3) & $90(80-95)$ & $80(68-90)$ & $80(74-90)$ & $90.67(-)$ & $54.67(-)$ \\
\hline
\end{tabular}

As a subset analysis, we implemented the same analysis as in Table 3 after excluding the students who attempted multiple times for the posttest. The result of this subset analysis is presented in Table 5. Although the students who attempted the post-test once were considered in the regression model, the emporium method achieved 12 points higher on average than the traditional method ( $\mathrm{p}$-value $=$ 5.26E-18). Therefore, there is no statistical evidence that multiple attempts boost the posttest score in the emporium method. The other covariates in the model have similar results except for the SAT verbal score, which became insignificant in the analysis without multiple attempts. 
The grade distribution of the two instructional methods was provided in Table 2. The final grade is determined by multiple factors such as test scores, homework assignments, quizzes, and attendance records. The course grade is another interesting outcome variable, which has somewhat different aspects from the post-test scores. Since the letter grades from A to F have the property of ordinality, an ordinal logistic regression could be an appropriate analytical method. However, the assumption of the proportional odds, which are indispensable for the ordinal logistic regression, was not satisfied ( $p$-value $<0.0001$ ). In this case, the nominal logistic regression is usually recommended but this model

Table 5. Relationship between the posttest score and the instructional methods with covariate adjustment for students who attempted only one time

\begin{tabular}{lcr} 
Variable (categories) & \multicolumn{1}{c}{ Estimate \pm SE } & p-value \\
\hline Intercept & $51.01 \pm 6.99$ & $1.44 \mathrm{E}-12$ \\
& & \\
Variation between semesters (reference level: Spring 2015) & $1.53 \mathrm{E}-13$ \\
Fall 2013 & $-29.14 \pm 3.82$ & $4.21 \mathrm{E}-05$ \\
Spring 2014 & $-13.66 \pm 3.3$ & 0.0002 \\
Fall 2014 & $-12.64 \pm 3.35$ & \\
& & 0.3518 \\
Class time (reference level: non-8 o'clock class) & \\
8 o'clock & $-1.4 \pm 1.5$ & 0.0013 \\
& & \\
Class day (reference level: MWF class) & 0.5020 \\
TTH & $4.56 \pm 1.41$ & \\
& & $2.94 \mathrm{E}-05$ \\
Gender (reference level: male) & 0.1121 \\
Female & $-0.91 \pm 1.35$ & $3.55 \mathrm{E}-06$ \\
& & \\
High School GPA & $5.55 \pm 1.37$ & $5.26 \mathrm{E}-18$ \\
SAT Verbal & $-0.02 \pm 0.01$ & \\
SAT Math & $0.06 \pm 0.01$ & \\
Instruction method (reference level: Traditional lecture) & $12.63 \pm 1.39$ & \\
Emporium & &
\end{tabular}

was too complicated with multiple factors in our case. Hence, after dichotomizing the letter grades into pass/fail status, we applied the logistic regression where grades A, B, and C are considered as a passing grade. Table 6 illustrates the result of the logistic regression analysis for the relationship between the pass status of the college algebra course and independent factors. Again, the independent factors for which the p-value is less than 0.05 is considered statistically significant. The odds ratio of the emporium method is not statistically different from that of the Traditional method ( $p$-value $=0.9301)$. The statistically insignificant result for the teaching method was not changed by the adjustment of ACT score instead of SAT Verbal and Math scores. Class time, SAT Verbal and Math scores were also statistically insignificant. However, class offering day, gender, and high school GPA are statistically significant factors, which affected the course grade. 


\section{Discussion}

The need to improve the instruction of college algebra is apparent in the high failure rates of students taking college algebra. In addition, the importance of understanding algebraic concepts cannot be underestimated. Failure rates of students in college algebra courses are much higher than failure rates in other freshman level courses (Herriott \& Dunbar, 2009). College algebra has been singled out as the course responsible for low retention of students (Sheldon, 2008). This study investigated the effectiveness of instructional methods: the emporium method and the traditional lecture method.

Table 6. Relationship between the course pass status and the instructional methods with covariate adjustment via logistic regression

Variable

\begin{tabular}{llrr} 
(categories) & Estimate \pm SE & OR $(95 \% \mathrm{CI})$ & p-value \\
\hline Intercept & $-3.3 \pm 1.15$ & & 0.0040
\end{tabular}

Variation between semesters (reference level: Spring 2015)

$\begin{array}{llll}\text { Fall 2013 } & -0.03 \pm 0.36 & 0.97(0.48-1.96) & 0.9362 \\ \text { Spring 2014 } & -0.21 \pm 0.29 & 0.81(0.46-1.44) & 0.4751 \\ \text { Fall 2014 } & 0.95 \pm 0.37 & 2.59(1.25-5.39) & 0.0107\end{array}$

Class time (reference level: non-8 o'clock class)
8 o'clock
$0.07 \pm 0.25$
$1.07(0.66-1.74)$
0.7846

Class day (reference level: MWF class)
TTH
$1.54 \pm 0.28$
$4.66(2.7-8.02)$
2.95E-08

Gender (reference level: male)

\begin{tabular}{llll}
\multicolumn{1}{c}{ Female } & $0.6 \pm 0.22$ & $1.82(1.18-2.83)$ & 0.0072 \\
High School GPA & $0.89 \pm 0.25$ & $2.43(1.48-3.98)$ & 0.0004 \\
SAT Verbal & $0 \pm 0.002$ & $1(1-1)$ & 0.7496 \\
SAT Math & $0 \pm 0.002$ & $1(1-1.01)$ & 0.1225
\end{tabular}

Instruction method (reference level: Traditional lecture)

\begin{tabular}{llll} 
Emporium & $-0.02 \pm 0.25$ & $0.98(0.6-1.59)$ & 0.9301 \\
\hline
\end{tabular}

The emporium method is one in which a student is actively involved in learning math by working problems and being able to receive feedback immediately. The effectiveness of the instructional methods was measured using scores on a posttest and final course grades. The posttest score is the most objective, uniform measure across the college algebra sections while the final grade and pass/failure rate are determined by many factors, which the section instructors set. As presented in Table 2, the results of the data analysis indicate that the mean score for students in the emporium sections was 82.16 while the mean score for the students in the traditional sections was 70.5. This result confirms that the students in the emporium sections outperformed students in the traditional sections of college algebra on the posttest by 12.63 points. This result aligns with the idea that Twigg (2007) asserted that students learn math best by doing math and not just sitting and passively listening. However, as also presented in Table 2, the data analysis indicates that the percentage of students in the emporium sections receiving passing grades was not statistically significant over the 
students in the traditional sections that passed the class. To compare the pass/failure rates for the two instructional methods, a uniform grading system needs to be introduced.

As shown in Table 3, the covariates were analyzed to examine their effect on students' performance on the posttest. The relation between the posttest score and the independent variables were examined using a multivariate general linear regression model. The independent variables with the significant impact on posttest performance were whether the class met on Tuesday and Thursdays or met on Mondays, Wednesdays, and Fridays, whether the class met at 8 o'clock versus meeting at a time other than 8 o'clock, and the high school GPA and SAT Math Score. The students enrolled in the courses taught on Tuesdays and Thursdays for both emporium and traditional sections performed better as measured by the posttest than students enrolled in classes that met on Mondays, Wednesdays, and Fridays. In addition, the students enrolled in the non 8 o'clock classes performed better than those students enrolled in the 8 o'clock classes. Also, as one might predict, high school GPA and SAT Math score were positively correlated with a higher posttest score.

The emporium method allows students to take the posttest up to three times. There was concern that this fact may alter the findings. However, Table 4 reveals that the students who took the posttest multiple times did not increase the posttest score in the emporium method. Table 5 provided the same data as found in Table 3 but excluded the emporium students that had taken the posttest multiple times. Again, the students using the emporium method outperformed the students using the traditional method by 12 points with statistical significance of $\mathrm{p}$-value $=5.26 \mathrm{E}-18$.

Table 6 shows that the effect that the emporium method had on final course grade was insignificant as compared to the traditional method. The only significant factors on final course grades were the days that class met (Tuesdays and Thursdays as compared to Monday, Wednesdays, and Fridays), gender and high school GPA. The classes that met on Tuesdays and Thursdays had the opportunity to have 75 minutes per class session, which allowed for students to have a longer time to take tests without interruption as compared to a student taking a test during the classes meeting on Mondays, Wednesdays, and Fridays where there was only 50 minutes to take their tests. Many students in the emporium sections waited until the class period a test was due to take the test; therefore, a student having 75 minutes to take a test multiple times has an advantage over a student having 50 minutes to take the test multiple times. Students that took the classes that met on Tuesdays and Thursdays earned higher course grades than students who took classes that met on Mondays, Wednesdays, and Fridays, females received better grades than males, and students with higher high school GPA earned better grades.

Although this study provided an empirical look at delivering college algebra using the emporium model of instruction, this study bears some limitations, which might lead to further studies. First, the instructors teaching in the traditional sections were not consistent in all of their assignments, such as tests and quizzes; however the pretests, the posttests, and the homework assignments for all sections of both the emporium and traditional classes were consistent. In addition, the emporium sections were consistent in all assignments. Second, the population for this study lacked racial diversity. Therefore, it may be a stretch to generalize the findings to all students. Third, several faculty members that taught in the emporium perceived that some students did not understand the rules of the emporium until late in the semester.

\section{Conclusion}

The emporium method is known for students' interactive personalized learning with computer aid and on-site assistance. The results of this study reveal that students enrolled in emporium classes outperformed students enrolled in traditional, lecture classes on posttest. The redesign and 
implementation of the emporium method of instruction was based on data suggesting that the students were not performing well under the traditional method of instruction. The emporium method combines several instructional components such as cooperative learning, online instruction, computer-assisted instruction, and immediate feedback from instructors. This empirical study investigated the effectiveness of the emporium method and the traditional lecture method in college algebra and trigonometry classes via rigorous statistical analyses. The main result of this study reveals that students enrolled in emporium classes outperformed students enrolled in traditional lecture classes on the posttest regardless of other factors such as gender, high school GPA, SAT score and ACT score. Students' performance in terms of pass rates was not significantly different between the emporium sections and the traditional lecture sections, which is partly due to heterogeneous grading policies across different sections. This study shows that the emporium method is potentially more effective than the traditional lecture method in improving student performance.

The emporium learning method shows much potential in improving students' performance in college algebra. Areas for future study include, but are not limited to, the following:

1) examine how the emporium affects students' dispositional learning, motivation, and attitudes toward learning college algebra

2) examine the effect of the emporium model of instruction on students of various gender, race, and ethnic background, and socioeconomic status levels

3) examine the effect of time of day and length of class period on students' performance in college algebra using the emporium and traditional learning methods

4) examine the effect of a faculty development emporium-training program on students' performance in college algebra.

\section{References}

Antil, L.R., Jenkins, J.R., and Wayne, S.K. (1998). Cooperative Learning: Prevalence, Conceptualizations, and the Relation Between Research and Practice, American Educational Research Journal, 35(3), 419-454.

Blimling, G. S., Whitt, E. J., \& Associates (1999). Good practice in student affairs: Principles to foster student learning. San Francisco, CA: Jossey-Bass.

Burch, K. J., \& Kuo, Y. (2010). TRADITIONAL VS. ONLINE HOMEWORK IN COLLEGE ALGEBRA. Mathematics and Computer Education, 44(1), 53-63.

Chickering, A. W., \& Gamson, Z. F. (1987). Seven principles for good practice in undergraduate education. AAHE Bulletin, 39(7), 3-7.

DePree, J. (1998). Small-Group Instruction: Impact on Basic Algebra Students. Journal Of Developmental Education, 22(1), 2-6.

Drijvers, P., Doorman, M., Kirschner, P., Hoogveld, B., \& Boon, P. (2014). The effect of online tasks for algebra on student achievement in grade 8. Technology, Knowledge and Learning, 19(1-2), 1-18.

Eddy, S., and Hogan, K. (2014). Getting under the hood: how and for whom does increasing course structure work?. CBE-Life Sciences Education, 13(3), 453-468.

Furner, J. M. \& Gonzalez-DeHass, A. (2011). How do students' mastery and performance goals relate to math anxiety? Eurasia Journal of Mathematics, Science, \& Technology Education, 7(4), 227-242.

Fullilove, R.E. and Treisman, P.U. (1990), Mathematics Achievement Among African American Undergraduates at the University of California, Berkeley: An Evaluation of the Mathematics Workshop Program. The Journal of Negro Education, 59 (3), 463-478.

Gillies, R.M. and Ashman, A.F. (2003). Co-Operative Learning: The Social and Intellectual Outcomes of Learning in Groups. New York: Routledge Falmer.

Gleason, J. (2012). Using Technology-Assisted Instruction and Assessment to Reduce the Effect of Class Size on Student Outcomes in Undergraduate Mathematics Courses. College Teaching, 60(3), 87-94.

Gordon, S. P. (2008). What's wrong with college algebra? Primus : Problems, Resources, and Issues in Mathematics Undergraduate Studies, 18(6), 516-541.

Hake, R.R. (1998), Interactive-engagement versus traditional methods: A six thousand-student survey of mechanics test data for introductory physics courses. American Journal of Physics, 66(1), 64.

Hegeman, J. S. (2015). Using Instructor-Generated Video Lectures in Online Mathematics Courses Improves Student Learning. Online Learning, 19(3), 70-87.

Herriott, S. R., \& Dunbar, S. R. (2009). Who takes college algebra? Primus : Problems, Resources, and Issues in Mathematics Undergraduate Studies, 19(1), 74-87. 
Lipnevich, A. A., MacCann, C., Krumm, S., Burrus, J., \& Roberts, R. D. (2011). Mathematics attitudes and mathematics outcomes of U.S. and Belarusian middle school students. Journal Of Educational Psychology, 103(1), $105-118$. doi:10.1037/a0021949

Liu, F \& Cavanaugh C. Factors influencing student academic performance in online high school algebra. Open Learning, 27(2), 149-167.

Mathai, E., \& Olsen, D. (2013). Studying the effectiveness of online homework for different skill levels in a college algebra course. Primus : Problems, Resources, and Issues in Mathematics Undergraduate Studies, 23(8), 671-682.

McCullagh, P., \& Nelder, J. A. (1989). Generalized Linear Models. doi:10.1007/978-1-4899-3242-6.

National Mathematics Advisory Panel. (2008). Foundations for Success: The Final Report of the National Mathematics Advisory Panel. Washington, D.C.: U.S. Department of Education.

Rakes, C. R., Valentine, J. C., McGatha, M. B., \& Ronau, R. N. (2010). Methods of instructional improvement in algebra: A systematic review and meta-analysis. Review of Educational Research, 80(3), 372. Retrieved from http://search.proquest.com/docview/756977989?accountid=12711, (accessed June 2014)

Robinson, D. R., Schofield, J. W., \& Steers-wentzell1, K. L. (2005). Peer and Cross-Age Tutoring in Math:Outcomes and Their Design Implications. Educational Psychology Review, 17(4), 327-362. doi:10.1007/s10648-005-8137-2

Shechtman, N., Haertel, G., Roschelle, J., Knudsen, K., \& Singleton, C. (2010). Design and development of the student and teacher mathematical assessments. Menlo Park, CA: SRI International.

Singh, K., Granville, M., \& Dika, S. (2002). Mathematics and science achievement: Effects of motivation, interest, and academic engagement. Journal of Educational Research, 95, 323-332. doi:10.1080/ 00220670209596607

Slavin, R. (2010). Co-operative learning: what makes group-work work? In Dumont, H., Istance, D., \& Benavides, F. (eds.), The Nature of Learning: Using Research to Inspire Practice. OECD Publishing.

Spradlin, K., \& Ackerman, B. (2010). The Effectiveness of Computer-Assisted Instruction in Developmental Mathematics. Journal Of Developmental Education, 34(2), 12-14,16,18,42.

Stacey, K., Chick, H., \& Kendal, M. (Eds.). (2004). The future of the teaching and learning of algebra: The 12th ICMI study. Dordrecht, Netherlands: Kluwer.

Stevenson, H. W., \& Newman, R. S. (1986). Long-term prediction of achievement and attitudes in mathematics and reading. Child Develop- ment, 57, 646-659. doi:10.2307/1130343

Strayhorn, T.L. (2011). Bridging the Pipeline: Increasing Underrepresented Students' Preparation for College Through a Summer Bridge Program. American Behavior Scientist, 55(2), 142-159.

Tienken, C. H., \& Maher, J. A. (2008). The Influence of Computer-Assisted Instruction on Eighth Grade Mathematics Achievement. RMLE Online, 32(3), 1-13.

Twigg, Carol A. (2011). The Math Emporium: Higher Education's Silver Bullet. Change: The Magazine of Higher Learning, 43(3), 25-34.

Watson, A. (2009). Paper 6: Algebraic reasoning. In T. Nunes, P. Bryant, \& A. Watson (Eds.), Key understandings in mathematics learning. London: Nuffield Foundation.

Zakaria, E., Solfitri, T., Daud, Y., \& Abidin, Z. Z. (2013). Effect of Cooperative Learning on Secondary School Students' Mathematics Achievement. Creative Education, 04(02), 98-100. doi:10.4236/ce.2013.42014. 